\title{
Varstvo osebnih podatkov pri delu psihologa
}

\author{
Urban Brulc \\ Urad Informacijskega pooblaščenca \\ urban.brulc@ip-rs.si
}

V naravi psihologovega dela je, da ima opravka s podatki posameznikov, torej s podatki o njihovih lastnostih, stanjih, razmerjih in ravnanjih. Ker se ti podatki praviloma nanašajo na določeno ali vsaj določljivo osebo, gre za osebne podatke. Ti so predmet posebne pravne ureditve varstva osebnih podatkov. Ker za področje psihologije posebnih predpisov v Sloveniji ni, pridejo v poštev splošna pravila varstva osebnih podatkov. Ena od izjem je klinična psihologija, za katero velja del zdravstvene zakonodaje. Pravila varstva osebnih podatkov torej imajo določen vpliv na delo psihologa, ki se v prvi vrsti kaže kot zavezanost poklicni molčečnosti. Čeprav je sistem varstva osebnih podatkov precej strog, vendarle ni absoluten $\mathrm{v}$ smislu, da podatkov ne bi bilo dopustno razkriti nikomur. Tako poleg splošnih pravil o nerazkrivanju in fizičnem zavarovanju osebnih podatkov obstaja nekaj posebnih pravnih podlag za njihovo razkritje drugim osebam. Po drugi strani ima psiholog na voljo zelo malo pravnih podlag za pridobivanje osebnih podatkov od drugih oseb, razen od posameznika, ki ga obravnava. $\mathrm{V}$ tem prispevku so predstavljene nekatere izbrane teme, ki se tičejo pridobivanja, hrambe in razkrivanja osebnih podatkov posameznikov, s poudarkom na pravicah posameznika, ki jih ima pri tem.

\section{Izhodišča}

Delo z ljudmi je običajno nujno povezano z zbiranjem, s hrambo, z uporabo, razkritjem in drugo obdelavo ${ }^{1}$ njihovih osebnih podatkov. Obdelava osebnih podatkov je deležna posebne pravne ureditve zato, da se v javnem interesu in interesu posameznikov zagotovi zakonita, poštena in sorazmerna obdelava osebnih podatkov ter da se preprečijo neustavni, nezakoniti in neupravičeni posegi v zasebnost in dostojanstvo posameznika (zVOP-1, členi 1-3). Sistem varstva osebnih podatkov je na splošno moč razdeliti na štiri področja: varstvo osebnih podatkov v ožjem smislu, kjer gre za vpra-

\footnotetext{
${ }^{1}$ Obdelava pomeni karkoli, kar upravljavec oz. njegovi zaposleni ali pogodbeniki počnejo z osebnimi podatki, npr. zbiranje, hramba, analiziranje, razmnoževanje, vpogled, urejanje, razkrivanje, posredovanje, sporočanje, objavljanje in podobno (člen 4 Splošne uredbe (E U) o varstvu podatkov). O obdelavi je moč govoriti, če se navezuje na neko zbirko osebnih podatkov ali pa če gre za avtomatizirano obdelavo, pri čemer slednja za delo psihologov ni značilna.
} 
šanja pravnih podlag za dopustnost obdelave osebnih podatkov; ${ }^{2}$ zavarovanje osebnih podatkov, kjer gre za vprašanja fizičnega varovanja osebnih podatkov (to so postopki in ukrepi za preprečitev slučajnega ali namernega nepooblaščenega uničevanja podatkov, njihove spremembe ali izgube ter nepooblaščene obdelave); posebne obveznosti upravljavcev osebnih podatkov (npr. vodenje evidence dejavnosti obdelav, obveznosti pri iznosu osebnih podatkov v tuje države); posebne pravice posameznikov (npr. pravica do seznanitve $z$ lastnimi osebnimi podatki).

\section{Okvir varovanja osebnih podatkov na področju psihologije}

Področje psihologije ima dve posebnosti, ki vplivajo tudi na varstvo osebnih podatkov. Prvič, poklicna področja, na katerih psihologi opravljajo svoje delo, so precej različna oz. razpršena, zaradi česar pridejo pri varstvu osebnih podatkov $v$ poštev predpisi $z$ več pravnih področij (npr. delovnopravna zakonodaja, šolska zakonodaja, zdravstvena zakonodaja, socialnovarstvena zakonodaja). Psihološka terapija in svetovanje (brez klinične psihologije, za katero se uporabljajo pravila, ki veljajo za zdravstveno dokumentacijo) sploh nista pokrita s področno zakonodajo. Druga posebnost je, da psihološki poklic niti na splošni ravni ni deležen enotne ureditve v področnem zakonu. Delno so nekatera vprašanja urejena v Kodeksu poklicne etike psihologov (Društvo psihologov Slovenije, 2008), vendar ta ni obvezujoč državni predpis, zaradi česar se je nanj moč sklicevati le takrat, kadar so posamezne določbe skladne s Splošno uredbo (EU) o varstvu podatkov in nekaterimi še veljavnimi deli Zakona o varstvu osebnih podatkov (zVOP1) ali s področno zakonodajo. Zato je Splošna uredba (E U) o varstvu podatkov tisti splošni in sistemski predpis, ki ga je treba ustrezno upoštevati tudi na področju psihologije, razen $v$ primerih, ko je posamezna dejavnost posebej urejena v področni zakonodaji. Povedano se kaže npr. pri vprašanju časa dopustne hrambe dokumentacije: ${ }^{3}$ če gre za dokumentacijo pri izvajalcih zdravstvene dejavnosti, se ta hrani v skladu z Zakonom o zbirkah po-

\footnotetext{
${ }^{2}$ To urejajo zlasti člen 6 in člen 9 Splošne uredbe (E U) o varstvu podatkov in seveda področni zakoni (npr. zakoni s področja vzgoje in izobraževanja, zakoni s področja delovnih razmerij, zakoni s področja zdravstva itd.). Pravna podlaga za zakonito obdelavo osebnih podatkov je lahko zakon, nadzakonski predpis ali privolitev.

${ }^{3}$ Po poteku roka hrambe je treba osebne podatke ali dokumente uničiti, nepovratno anonimizirati, izročiti stranki ali predati pristojnemu arhivu, če so za slednje izpolnjeni posebni pogoji. To velja le, če je prenehal namen obdelave osebnih podatkov, ali če je potekel zakonsko predpisan rok. Pred potekom zakonsko določenih rokov, osebnih podatkov ni dopustno uničiti.
} 
datkov s področja zdravstvenega varstva (splošni rok za najpomembnejšo zdravstveno dokumentacijo je 10 let po smrti pacienta) in Enotnim klasifikacijskim načrtom za razvrščanje poslovne in zdravstvene dokumentacije $\mathrm{z}$ roki hranjenja za zavode s področja zdravstva; ${ }^{4}$ če gre za zbirko podatkov o učencih, ki potrebujejo pomoč oz. svetovanje $\mathrm{v}$ šoli, se ta hrani še eno leto po zaključku šolanja učenca (Zakon o osnovni šoli (z osn), člen 98). če gre za dokumentacijo s področja zasebnega svetovanja, roke določi izvajalec sam (npr. 5 let ali eno leto po zaključku obravnave), ${ }^{5}$ posameznik pa $\mathrm{v}$ hrambo privoli.

V nadaljevanju so predstavljena nekatera izbrana področja varstva osebnih podatkov, ki se navezujejo na delo psihologa, pri čemer gre za teme, ki so načeloma skupne vsem dejavnostim, v katerih psihologi običajno opravljajo delo. Kompetence psihologov na tem področju se navezujejo na pravno in etično razumevanje stroke.

\section{Kompetence psihologov za ustrezno delo z osebnimi podatki}

Psiholog mora imeti kompetence za refleksijo svojega dela predvsem v občutljivih situacijah. Prav tako potrebuje ključna znanja in informacije o zakonskih podlagah pri svojem delu. Nekateri vidiki dela so za psihologe pomembni ne glede na področje dela, kar bomo predstavili v spodnjih primerih.

\section{Ločeno ali razpršeno vodenje dokumentacije}

Zlasti na področju terapevtskega in svetovalnega dela (npr. zasebno svetovanje ali terapija, šolska svetovalna služba, klinična psihologija, socialnovarstveni zavodi) se v praksi ločeno vodi »uradna « ${ }^{6}$ dokumentacija (npr. v osebni mapi - psihološkem dosjeju) ter osebna dokumentacija v obliki psihologovih osebnih zapiskov ali zabeležk. To sicer dopušča tudi Kodeks poklicne etike psihologov (Društvo psihologov Slovenije, 20o8), vendar se postavlja vprašanje, ali je takšna praksa dopustna tudi z vidika varstva oseb-

\footnotetext{
${ }^{4}$ Dostopen je na spletni strani Ministrstva za zdravje.

${ }^{5}$ Pri internem določanju rokov se upošteva pravilo o tem, da se osebni podatki lahko shranjujejo le toliko časa, dokler je to potrebno za dosego namena, zaradi katerega so se zbirali ali nadalje obdelovali (člen 5 Splošne uredbe (E U) o varstvu podatkov), in pravilo, da je podatke smiselno hraniti toliko časa, kot so možne razne oblike nadzora ter kot so možni civilnopravni zahtevki na sodišču ali kazenski pregon.

${ }^{6} \mathrm{Ne}$ gre za pravo uradno dokumentacijo, ki jo vodijo različni upravni organi na podlagi zakona, temveč je mišljena formalna dokumentacija, tj. tista, ki se jo bolj ali manj obvezno vodi po ustaljeni praksi ali po posebnih predpisih. Klasična primera sta psihološki dosje in zbirka podatkov o učencih, ki potrebujejo pomoč in svetovanje.
} 
nih podatkov. Splošna uredba (E U) v členu 2 določa, da se določbe uredbe ne uporabljajo za obdelavo osebnih podatkov s strani fizične osebe pri izvajanju osebne ali domače dejavnosti (osebna ali družinska raba). Vodenje osebnih zabeležk (čeprav bi te praviloma ustrezale definiciji zbirke osebnih podatkov) je zato dopustno, zabeležke pa celo uživajo »imuniteto« v razmerju do pravil varstva osebnih podatkov. Toda to velja le do trenutka, ko so podatki naključno ali po volji psihologa razkriti tretjim osebam izven ožjega kroga oseb iz osebne, družinske oz. domače rabe. Zato mora psiholog obvezno skrbeti za fizično zavarovanje osebnih zabeležk pred izgubo, nenamernim razkritjem ipd. ter skrbeti, da podatkov ne razkriva neupravičenim osebam.

Pogosto se tudi dogaja, da je "uradna« dokumentacija zelo skopa in vsebuje le nekaj ključnih kratkih zapisov, večina strokovno pomembnih zapisov pa se nahaja v obliki osebnih zabeležk. Taka praksa je nedopustna ( $v$ izjemnih primerih bi lahko šlo tudi za prekršek) in tudi z vidika stroke neustrezna.

Poseben primer ločenega vodenja dokumentacije je vodenje "uradne« dokumentacije na več mestih, npr. tako, da se pomembnejša dokumentacija vodi kot glavna in navzven edina dokumentacija, drugi zapisi (npr. manj pomembni ali občutljivejši) pa se vodijo ločeno, torej v drugih mapah in na drugih lokacijah znotraj prostorov upravljavca ali celo izven. Tu je treba opozoriti, da taka praksa ni dopustna (ni pa prekršek) in da nasproti zunanjim zakonitim uporabnikom podatkov nima učinkov. To pomeni, da se bo vsa dokumentacija, ne glede na razpršenost hrambe, štela kot celota in da bo zunanji uporabnik, ki ima zakonsko podlago za pridobitev podatkov (npr. sodišče), upravičen do pridobitve celotne dokumentacije, ne glede na lokacijo hrambe oz. način vodenja.

Nasvet. Ločeno vodenje dokumentacije ne sme iti na račun popolnega in strokovnega vodenja "uradnega" dela dokumentacije in tudi ne na račun pravic strank ${ }^{7}$ do seznanitve z lastnimi podatki ali na račun pravic zunanjih zakonitih uporabnikov podatkov.

\section{Psihološki podatek kot občutljiv osebni podatek}

Osebni podatki se praviloma ne razvrščajo v različne vrste ali skupine podatkov, ker za to ni posebne potrebe, saj so vsi deležni enakega varstva. Izjema so le posebne kategorije osebnih podatkov, ki se po ZVOP-1 ime-

\footnotetext{
${ }^{7}$ V tem prispevku večinoma uporabljam pojem »stranka«, druge možnosti so še npr. »obravnavanec«, »klient«, "pacient« ali "posameznik«.
} 
novali občutljivi osebni podatki. To so podatki o rasnem, narodnostnem poreklu, političnem, verskem ali filozofskem prepričanju, članstvu v sindikatu, zdravstvenem stanju, genetski podatki in podatki o spolnem življenju, pogojno tudi podatki o vpisu ali izbrisu $v$ ali iz kazenske evidence ali prekrškovnih evidenc ter biometrični podatki. ${ }^{8}$

Zanimivo je, da se psiholog pri svojem delu lahko sreča s prav vsemi vrstami občutljivih osebnih podatkov. Zato mora pri njihovi obdelavi upoštevati dve posebni pravili:

- Občutljivi osebni podatki se lahko prenašajo preko telekomunikacijskih omrežij, če se posredujejo z uporabo kriptografskih metod (gre za šifriranje sporočil) in elektronskega podpisa tako, da je zagotovljena njihova nečitljivost oz. neprepoznavnost med prenosom (klasičen primer neustreznega zavarovanja je pošiljanje občutljivih osebnih podatkov prek navadne e-pošte, seveda pod pogojem, da je posameznik, na katerega se podatki nanašajo, določen ali določljiv). ${ }^{9}$ Poudarek pravila je na šifriranju, ker elektronski podpis pošiljatelja sam po sebi pravzaprav ne prispeva $k$ večji varnosti posredovanih podatkov, pač pa (poleg seveda potrditve istovetnosti pošiljatelja) zagotavlja le celovitost sporočila, tj. da to na poti ni bilo spremenjeno. Šifriranje sporočil se lahko zagotovi na različne načine. V praksi se kot zadovoljiv način šteje pošiljanje sporočila v zgoščeni in šifrirani datoteki s pomočjo brezplačnega programa za zgoščevanje datotek (npr. 7-ZIP), pri čemer je treba geslo za branje prejemniku sporočiti po drugi varni poti.

- Na splošno je treba na področju zavarovanja občutljivih osebnih podatkov po možnosti poskrbeti za višjo raven varstva v primerjavi z »navadnimi« osebnimi podatki ${ }^{10}$ (npr., priporočljivo je, da so računalniški nosilci tovrstnih podatkov šifrirani in da se papirne dokumente po navadni pošti pošilja priporočeno ali priporočeno s povratnico).

Zanimivo je vprašanje, ali se rezultate testov in interpretacijske podatke, npr. v psihološkem izvidu ali mnenju, šteje za podatke o zdravstvenem stanju (npr. podatek, da ima stranka visok suicidalni potencial; da ima stranka obsesivno-kompulzivno motnjo; da je klientov indeks motene percepcije in mišljenja P T I o,8). Glede tega vprašanja predpisi ne dajejo jasnega odgo-

\footnotetext{
${ }^{8}$ Člen 9 Splošne uredbe (EU) o varstvu podatkov. Več o občutljivih osebnih podatkih glej v Brulc (2013).

${ }^{9}$ To je zahteva drugega odstavka 14. člena zVoP-1.

${ }^{10} \mathrm{Na}$ to je moč sklepati npr. iz določbe tretjega odstavka 24. člena ZVOP-1.
} 
vora, praksa pa tudi ni ustaljena. Praviloma se podatki o zdravstvenem stanju navezujejo na pacientove podatke, katerih izvor je v zdravstveni oskrbi v klasičnem smislu, torej zdravstveni podatki. Vendar se priporoča, da se omenjeni psihološki podatki obravnavajo kot občutljivi osebni podatki, saj se ta pojem v praksi razume široko in ne zajema zgolj podatka o zdravstvenem stanju v ožjem smislu (npr., tudi zgolj podatek o uporabljenem psihodiagnostičnem sredstvu ali izvedeni operaciji je podatek o zdravstvenem stanju), poleg tega ga ZVOP-1 izrecno ne navezuje le na zdravstveno dejavnost. Seveda ni nobenega dvoma, da se podatke s področja klinične psihologije šteje kot podatke o zdravstvenem stanju.

Nasvet. $V$ dvomu je treba psihološke podatke - tu so mišljeni podatki o psihološki obravnavi, anamneza, rezultati obravnave, rezultati testov, vključno s psihološkimi diagnozami ipd. - šteti za občutljive osebne podatke ter jim pri obdelavi nameniti posebno skrb.

\section{Pridobivanje in posredovanje osebnih podatkov - privolitev}

Za pridobivanje podatkov od stranke je $\mathrm{v}$ večini primerov, zlasti na področju zasebne svetovalne ali terapevtske dejavnosti, kot pravna podlaga na voljo strankina privolitev (celo šolska dokumentacija otrok, ki potrebujejo pomoč in svetovanje, je vezana na privolitev staršev ali otroka). ${ }^{11}$ Za samo zbiranje podatkov neposredno od stranke (npr. identifikacijski in kontaktni podatki, dokumenti, ki jih stranka prinese sama, testiranje, anamneza ipd.) pisna privolitev teoretično ni potrebna, saj posameznik s tem, ko aktivno sodeluje pri obravnavi, privoli tudi $v$ dajanje in zbiranje podatkov. Toda posameznik mora biti še pred privolitvijo obveščen o tem, kateri podatki se zbirajo, $v$ kateri zbirki ali zbirkah, kdo je njihov upravljavec in morebitni zunanji uporabnik, koliko časa se hranijo, kakšen je namen njihovega zbiranja in kako se izvaja obdelava (vrsta obdelave in način). ${ }^{12}$ To obveščanje je najlažje zagotoviti v pisni obliki, poleg tega si psiholog s tem zagotovi pisni dokaz o tem, da je bil posameznik resnično obveščen o vseh vidikih obdelave podatkov ter, seveda, da je resnično privolil.

\footnotetext{
${ }^{11} \mathrm{~V}$ delovnih razmerjih je privolitev omejena zaradi neenakosti med delodajalcem in delavcem ter zaradi pravila, da se lahko zbirajo le podatki, ki so potrebni zaradi uresničevanja pravic in obveznosti iz delovnega razmerja ali v zvezi z delovnim razmerjem. V zdravstvu privolitev ni posebej omejena.

${ }^{12}$ Obveščanje o namenu zahteva tudi Kodeks poklicne etike psihologov (Društvo psihologov Slovenije, 2008). Obveščanje posameznikov po novem urejata člen 13 in 14 Splošne uredbe (E U) o varstvu podatkov.
} 
Privolitvi je treba posvetiti še več pozornosti:

- če gre za posredovanje ali razkritje posameznikovih osebnih podatkov tretjim (zunanjim) osebam, ki za seznanitev nimajo izrecne zakonske podlage (npr. razkritje osebnih podatkov za potrebe supervi$z i j e) ;{ }^{13}$ in

- če gre za posebno uporabo podatkov ali dokumentov, tj. za namen, ki presega prvotni ali osnovni namen (npr. uporaba podatkov za raziskovalni namen, pri čemer se bodo s podatki poleg psihologa, ki posameznika obravnava, seznanile tudi druge osebe). ${ }^{14}$

Tu domneva privolitve ne velja, zato mora biti slednja vedno izrecna (priporočljivo je, da je tudi pisna) ter dana na podlagi predhodno sporočenih informacij o namenu, načinu, obsegu, času in udeležencih obdelave podatkov. Seveda privolitev ni smiselna oz. ni potrebna, če sta izpolnjena dva pogoja:

- če je želena obdelava osebnih podatkov že dopuščena ali zapovedana z zakonom ali

- če se obdelava osebnih podatkov izvaja z nepovratno (absolutno) anonimiziranimi podatki.

Nasvet. Če za določeno obdelavo osebnih podatkov ni na voljo ustrezne zakonske podlage, je treba od stranke pridobiti privolitev, praviloma v pisni obliki. Pogoj za veljavnost privolitve je popolna informiranost o pomembnih vidikih obdelave - kateri osebni podatki se bodo obdelovali, kako (vrsta obdelave, način in lokacija), za kakšen namen, koliko časa in komu bodo posredovani.

\section{Posredovanje osebnih podatkov - zakonska podlaga}

Za razkritje ali posredovanje osebnih podatkov drugim osebam ${ }^{15}$ mora biti na voljo pravna podlaga. Pri tem ni važno, ali gre za občutljive osebne po-

${ }^{13}$ Če za potrebe supervizije stranka ni določena ali določljiva, privolitev ni potrebna.

${ }^{14} \mathrm{Na}$ tem mestu velja omeniti splošno ureditev v 17. in 23. členu ZVOP-1, po katerih je osebne podatke brez privolitve dopustno uporabljati za znanstveno-raziskovalni namen $v$ treh primerih: če gre za interno raziskavo, ki jo izvaja upravljavec (psiholog ali organizacija, pri kateri opravlja delo) sam, ali če se podatke anonimizira še pred posredovanjem zunanjemu nosilcu raziskave, ali če je posameznik že umrl in za časa življenja ni prepovedal take uporabe podatkov.

${ }^{15}$ Gre pravzaprav za tretje osebe, ker so mišljene osebe, ki niso obravnavani posameznik in ne psiholog, ki posameznika obravnava. Pri tem gre lahko za posameznike (npr. strankini 
datke ali ne. Pravna podlaga je lahko določena ${ }^{16} \mathrm{v}$ nekem zakonu ${ }^{17}$ (lahko je to evropska uredba, ZVOP-1 ali pa nek področni zakon), če pa te ni, je možna tudi privolitev.

Neredko se zgodi, da nek državni (oblastni) organ zaprosi za osebne podatke stranke, s katerimi razpolaga psiholog ali organizacija, pri kateri psiholog opravlja delo. Na splošno velja, da imajo oblastni organi (pri tem ne gre nujno za organe, pač pa tudi druge organizacijske oblike, ki so nosilci javnih pooblastil; tak primer so centri za socialno delo) v svojih področnih zakonih na voljo pravno podlago za pridobivanje določenih osebnih podatkov, ki so potrebni za izvajanje njihovih pristojnosti (npr. sodišča ne glede na vrsto postopka, državna tožilstva, policija, upravni organi, inšpekcijske službe ipd.).

Če je psiholog klican na sodišče kot priča, ne gre za enak položaj, kot če prejme pisno zahtevo za posredovanje podatkov ali dokumentacije. ${ }^{18} \mathrm{Raz}-$ lika je v tem, da ima psiholog pri pričanju v pravdnem postopku možnost, da odreče pričanje o dejstvih, za katera je izvedel pri opravljanju svojega poklica, če velja dolžnost, da mora ohraniti kot tajnost tisto, kar je izvedel pri opravljanju tega poklica (Zakon o pravdnem postopku (Z P P), člen 231). Ta pogoj je izpolnjen, ker etični kodeks določa posamezne elemente poklicne molčečnosti (Wedam Lukić, 1994; 1996). ${ }^{19}$ Vendar tu ni mišljeno vsako psihologovo delo (npr. delo v kadrovski službi, če se neposredno ne nanaša na psihologijo), temveč le klasično delo psihologa pri delu s posameznimi strankami. Drugi pogoj za odrek pričanja je, da gre za podatke, ki izvirajo iz tega dela in ne npr. iz osebnega življenja. Psiholog ne sme odreči pričanja, če je razkritje določenih dejstev potrebno zaradi javne koristi ali koristi koga drugega, če je ta korist večja kakor pa ohranitev skrivnosti (Z P P, člen 232). Tak primer so podatki o zlorabi otroka, če so podane okoliščine, zaradi katerih je razkritje zelo pomembno za interese otroka, ker

svojci, drug psiholog) ali pravne osebe oz. organizacije (npr. šole, državni organi, izvajalci zdravstvene dejavnosti, raziskovalne organizacije).

${ }^{16}$ Včasih je pravna podlaga izrecno in jasno določena, dostikrat pa je pri iskanju pravne podlage potrebna ustrezna interpretacija določb.

${ }^{17}$ Praviloma je to lahko le zakon in ne podzakonski predpis, ker tako zahteva Ustava Republike Slovenije. V praksi je kar nekaj podzakonskih predpisov (npr. pravilnikov), ki dopuščajo ali zapovedujejo določeno obdelavo osebnih podatkov.

${ }^{18}$ Po novem lahko priča pod določenimi pogoji izjavo poda tudi pisno. Tako obliko pričanja je treba ločiti od sodnih poizvedb, s katerimi želi sodišče od psihologa ali organizacije pridobiti že obstoječe podatke (npr. kopijo psihološkega izvida ali izpis iz računalniške evidence).

${ }^{19} \mathrm{O}$ tem, da obveznost varovanja poklicne skrivnosti ni nujno predpisana le z zakonom, glej Wedam Lukić (1994, 1996). 
bo na tej podlagi npr. deležen ustrezne institucionalne oskrbe, ločen od storilca, deležen odškodnine ali preživnine ipd.

Za razliko od Z P P Zakon o kazenskem postopku ( $\mathrm{ZK} \mathrm{P}$ ) v 236. členu med osebami, ki so oproščene pričanja, izrecno določa tudi psihologe. Ta privilegij priče ne velja le v tistem kazenskem postopku, ki teče zaradi kaznivih dejanj zoper spolno nedotakljivost iz XIX. poglavja Kazenskega zakonika (K Z-1), kaznivega dejanja zanemarjanja mladoletne osebe in surovega ravnanja po 192. členu in kaznivega dejanja trgovine $z$ ljudmi po 113. členu $\mathrm{K} Z-1$, če gre v vseh primerih za mladoletnega oškodovanca.

V pravdnem in kazenskem postopku je torej dopustno »izdati« poklicno skrivnost zaradi splošne koristi ali upravičenega interesa javnosti ali zaradi koristi koga drugega, če je ta korist večja kakor ohranitev skrivnosti ali če je z zakonom določena odveza dolžnosti varovanja skrivnosti. Če pod temi pogoji v kazenskem postopku psiholog ne uveljavlja oprostitve pričanja (torej se odloči, da bo pričal in razkril podatke), to razkritje podatkov ne bo kaznivo v smislu kaznivega dejanja neupravičene izdaje poklicne skrivnosti. ${ }^{20}$

Ni izključeno, da psiholog nastopa kot priča tudi v upravnem postopku pred upravnim organom (npr. pred centrom za socialno delo ali upravno enoto). Tudi tu velja, da sme odreči pričanje:

- če na posamezna vprašanja ne bi mogel odgovoriti, ne da bi prekršil dolžnost oz. pravico varovati poklicno tajnost; ali

- če gre za dejstva, ki jih je zvedel pri svojem poklicu ali dejavnosti, če velja dolžnost, da mora ohraniti kot tajnost tisto, kar je zvedel pri opravljanju takega poklica ali dejavnosti (Zakon o splošnem upravnem postopku ( $\mathrm{ZU}$ P), člen 183).

Posebna skupina zunanjih uporabnikov osebnih podatkov so strankini svojci. Na splošno ti niso upravičeni do seznanitve s podatki ali dokumentacijo, razen (alternativno):

- če gre za zakonite dediče prvega ali drugega dednega reda, ki za seznanitev z osebnimi podatki že umrle stranke izkažejo pravni interes (npr. da potrebujejo podatke za zavarovalnico, ker morajo dokazati določeno dejstvo, ali da potrebujejo podatke v zapuščinskem sodnem

${ }^{20} \mathrm{Za}$ to kaznivo dejanje je sicer zagrožena denarna kazen ali kazen zapora do enega leta, kaznivo dejanje pa se ne preganja po uradni dolžnosti, pač pa na zasebno (kazensko) tožbo (K Z-1, člen 142). 
postopku ali kakšnem drugem sodnem postopku), stranka pa je umrla ter za časa življenja seznanitve ni prepovedala ( $\mathrm{VVOP}-1$, člen 23, 2. odstavek);

- če je stranka v to posebej privolila;

- če je stranka nesposobna odločanja (nerazsodna), pa je kdo od svojcev formalno postavljen za skrbnika (Društvo psihologov Slovenije, 2008, člen 18);

- če je svojec soobravnavanec in je možno posamezne zapise šteti kot njune skupne;

- če gre za področje klinične psihologije, so na podlagi 45. člena Zakona o pacientovih pravicah ( $\mathrm{P}$ P acP) do podatkov upravičeni zakonec, zunajzakonski partner, partner iz istospolne skupnosti, starši, posvojitelji, stari starši, otroci oz. posvojenci, vnuki ter bratje in sestre ter celo pacientu druge bližnje osebe, ki to dejstvo izkažejo; pogoj za razkritje je, da pacient ni prepovedal razkritja ali tega ne more storiti zaradi slabega zdravstvenega stanja (ta pogoj je treba razumeti $v$ smislu, da ga je treba pred razkritjem pozvati, da se do tega opredeli);

- če gre za področje klinične psihologije, so do seznanitve upravičeni tudi tisti svojci, ki so v skladu z Z P ac P upravičeni do odločanja o zdravstveni oskrbi privolitveno nesposobnega pacienta. ${ }^{21}$

Kodeks poklicne etike psihologov Slovenije (Društvo psihologov Slovenije, 2002) je v drugem stavku 21. člena predvideval poseben primer dopustnega razkritja osebnih podatkov (izjemno razkritje), vendar določba ni v celoti skladna z ZVOP-1. ${ }^{22}$ Zato je dopustno, da psiholog izjemoma razkrije osebne podatke le:

- če je to nujno potrebno za varovanje življenja ali telesa stranke (to pogojno omogoča člen 6 (točka d) Splošne uredbe (E U) o varstvu podatkov) - v tem delu je kodeks skladen s pravili varstva osebnih podatkov;

- če je obdelava nujno potrebna za varovanje življenja ali telesa druge osebe, kadar stranka, na katero se osebni podatki nanašajo, fizično ali poslovno ni sposobna dati svoje privolitve (to pogojno omogoča

\footnotetext{
${ }^{21}$ Ti so v izključujočem vrstnem redu: skrbnik, zakonec ali zunajzakonski partner, polnoletni otroci, starši, bratje in sestre, stari starši in vnuki.

${ }^{22}$ Kodeks določa, da sme psiholog od obveznosti popolnega ščitenja podatkov odstopiti le v izjemnih primerih, ko je ogroženo življenje obravnavanca ali življenje drugih ljudi ali ko gre za zlorabo otrok.
} 
člen 9 (točka c) Splošne uredbe (E U) o varstvu podatkov) - v tem delu kodeks ni skladen z ZVOP-1.

Primer »zlorabe otrok«, ki ga predvideva kodeks, pride v poštev le, če zloraba dosega standard varovanja življenja in telesa stranke ali druge osebe iz zgornjih alinej. Kljub delni neskladnosti z Z VO P-1 so pogoji iz nekdanjega 21. člena Kodeksa poklicne etike psihologov Slovenije (Društvo psihologov Slovenije, 2002) lahko upravičen razlog za to, da se psiholog kot priča v sodnem postopku ne odpove pričanju.

Nasvet. Psiholog v vlogi priče na sodišču lahko odreče pričanje, vendar to ni smiselno, če gre zgolj za sporočanje istih informacij, kot izhajajo iz dokumentacije (do te je sodišče upravičeno že na posebni pravni podlagi), in na splošno ni možno, če je razkritje določenih dejstev potrebno zaradi javne koristi ali koristi koga drugega, če je ta korist večja kakor pa ohranitev skrivnosti.

\section{Seznanitev z lastnimi osebnimi podatki}

Stranka ima pravico do seznanitve $\mathrm{z}$ lastnimi osebnimi podatki in dokumentacijo, ki se nanaša nanjo. ${ }^{23}$

Aktivnost ali vaja

V nadaljevanju si poglejmo nekaj posebnih primerov seznanitve.

1. Stranka zaprosi za kopijo zapisov o svoji obravnavi, ki se ne vodijo v osebnem dosjeju, a hkrati ne gre za psihologove osebne zabeležke: $\mathrm{v}$ tem primeru je stranka upravičena do seznanitve, ker se ta pravica ne razteza zgolj na osebni dosje, ${ }^{24}$ temveč tudi na druge zbirke ali dokumente oz. njihove dele, ki vsebujejo strankine osebne podatke.

2. Stranka zaprosi za vpogled v osebni dosje, pri čemer psiholog oceni, da bi bila stranki z razkritjem povzročena resna škoda (npr. poslabšanje zdravstvenega stanja, poslabšanje psiholoških težav, tveganje za samomor,

\footnotetext{
${ }^{23}$ Pravne podlage so v 38. členu Ustave Republike Slovenije, v členu 12 in členu 15 Splošne uredbe (E U) o varstvu podatkov in 41. členu $\mathrm{ZPacP}$ (ureditev $\mathrm{V} \mathrm{ZPaCP}$ je tudi s postopkovnega vidika nekoliko drugačna od ureditve po ZV OP-1). Tako je določal tudi 16. člen Kodeksa poklicne etike psihologov Slovenije (Društvo psihologov Slovenije, 2002). Zoper zavrnitev ali molk (če upravljavec stranki ne odgovori v enem mesecu, kot to določa uredba) je možna pritožba pri Informacijskem pooblaščencu.

${ }^{24}$ Stari Kodeks poklicne etike psihologov Slovenije (Društvo psihologov Slovenije, 2002) se v 16. členu omejuje le na osebni dosje.
} 
tveganje za ogrozitev drugih oseb), saj je njeno stanje zelo resno, rezultati testiranja pa zaskrbljujoči: predpisi ne določajo nobenih omejitev pravice do seznanitve, ki bi veljali na področju psihologije. Tudi na področju klinične psihologije Z P ac P ne omogoča (več) terapevtskega privilegija, če stranka izrecno zahteva popolno seznanitev ne glede na posledice. Zato možnost omejitve razkritja, ki jo je določal 16. člen starega Kodeksa poklicne etike psihologov Slovenije (Društvo psihologov Slovenije, 2002), ne velja.

3. Stranka zaprosi za kopijo psihologove osebne beležke, saj meni, da so $v$ njej zelo relevantni zapisi o njeni anamnezi, stanju in rezultatih obravnave, te pa bi rada predložila $v$ nekem uradnem postopku kot dokaz: glede na dosedanjo prakso Informacijskega pooblaščenca bi psiholog tako zahtevo lahko zavrnil s sklicevanjem na 7. člen zVOP-1 oziroma na člen 2 Splošne uredbe (E U) o varstvu podatkov. ${ }^{25}$

4. Stranka zaprosi za kopijo izpolnjenega psihodiagnostičnega sredstva (npr. RBANS test) zato, da bo pri svojem strokovnjaku preverila rezultate: čeprav pravica do seznanitve ni izrecno omejena, iz prakse Informacijskega pooblaščenca izhaja, da je tako zahtevo izjemoma možno omejiti tako, da stranka pridobi le kopijo svojih ročnih zapisov ter psihologovih zapisov, brez prednatisnjenega avtorskega dela psihodiagnostičnega sredstva. ${ }^{26}$ To je tudi skladno $z$ usmeritvami iz 40. člena starega Kodeksa poklicne etike psihologov Slovenije (Društvo psihologov Slovenije, 2002). Čeprav na splošno pooblaščenec ne more imeti več pravic kot stranka sama, verjetno ne bi bilo sporno izročiti kopije zahtevanih dokumentov strankinemu pooblaščencu, ki je usposobljen psiholog.

5. Oče mlajšega mladoletnika bi kot otrokov zakoniti zastopnik (torej v imenu stranke) rad vpogledal $v$ otrokove (torej strankine) slikovne in pisne izdelke. Vsebina teh je takšna, da bi lahko zaradi očetovega odziva otrok utrpel kakršnokoli nasilje ali zlorabo. V izjemnih primerih ni izključeno, da se, s sklicevanjem na ustavne pravice ali pravice iz zavezujočih mednarodnih pogodb (npr. Konvencija o otrokovih pravicah), pravica zakonitega zastopnika omeji v korist oz. za varovanje upravičenih interesov otrok. ${ }^{27}$

Nasvet. Stranki zgolj zato, ker zahteva seznanitev z lastnimi osebnimi

\footnotetext{
${ }^{25} \mathrm{O}$ tem npr. odločba Informacijskega pooblaščenca št. 0710-1/2013.

${ }^{26} \mathrm{O}$ tem npr. odločba Informacijskega pooblaščenca št. 0710-33/2008.

${ }^{27} \mathrm{O}$ tem npr. odločba Informacijskega pooblaščenca št. 0710-27/2009.
} 
podatki, ne gre zameriti, saj s tem uresničuje ustavno pravico. Predpisi ne določajo posebnih omejitev pri uresničevanju pravice do seznanitve; le izjemoma je zaradi varovanje upravičenih interesov drugih oseb možno $v$ celoti ali delno zavrniti zahtevo stranke.

\section{Zaključek}

Pravila varstva osebnih podatkov od psihologa zahtevajo skrbnost pri pridobivanju, hrambi, uporabi, posredovanju ali razkrivanju in drugih vrstah obdelave podatkov ali dokumentov, ki se nanašajo na določenega ali določljivega posameznika. Ta skrbnost pomeni, da podatkov ni dopustno obdelovati brez pravne podlage ( $\mathrm{v}$ zakonu ali privolitvi) ter da je treba predvideti in izvrševati postopke in ukrepe za fizično varovanje podatkov pred izgubo, uničenjem, nepooblaščenim dostopom in spreminjanjem podatkov. Posebno pozornost je treba posvetiti občutljivim osebnim podatkom, s katerimi se psihologi neredko srečujejo.

Razpolaganje z osebnimi podatki psihologu prinaša tudi nekatere dodatne ali posebne obveznosti do strank, zlasti zagotavljanje pravice do seznanitve $z$ lastnimi osebnimi podatki. Kodeks poklicne etike psihologov Slovenije (Društvo psihologov Slovenije, 2008) kot nezavezujoč akt vsebuje nekaj usmeritev, ki so skladne s pravili varstva osebnih podatkov, vendar vsebuje tudi nekaj določb, ki s temi pravili niso skladne.

\section{Literatura}

Brulc, U. (2013). Razmerje med splošnimi pravili varstva občutlivih osebnih podatkov in specialnimi pravili o javni dostopnosti arhivskega gradiva. V D. Hančič, G. Jenuš in N. Strajnar (ur.), Odstiranja zamolčanega: zbornik prispevkov (str. 318-337). Študijski center za narodno spravo.

Društvo psihologov Slovenije. (2002). Kodeks poklicne etike psihologov Slovenije.

Društvo psihologov Slovenije. (2008). Kodeks poklicne etike psihologov.

Wedam Lukić, D. (1994). Uporaba zdravstvene dokumentacije v sodnih postopkih. Pravnik, 49(1/3), 37-45.

Wedam Lukić D. (1996). Varstvo osebnih podatkov v civilnih sodnih postopkih. Podjetje in delo, št. 5/6, 914-921.

\section{Pravni viri}

Kazenski zakonik (K Z-1). Uradni list Republike Slovenije, št. 50/12 - uradno prečiščeno besedilo, 6/16 - popr., 54/15, 38/16 in 27/17.

Uredba (E U) 2016/679 Evropskega parlamenta in Sveta z dne 27. aprila 2016 o varstvu posameznikov pri obdelavi osebnih podatkov in o prostem pretoku takih podatkov ter o razveljavitvi Direktive 95/46/E S (Splošna uredba o varstvu podatkov). Uradni list Evropske unije L 119/1-88. 
Zakon o kazenskem postopku (Z K P). Uradni list Republike Slovenije, št. 32/12 - uradno prečiščeno besedilo, 47/13, 87/14, 8/16 - odl. U S, 64/16 - odl. Us, 65/16 - odl. U S, 66/17 - O R Z K P 153,154 in 22/19.

Zakon o osnovni šoli (zosn). Uradni list Republike Slovenije, 81/o6 - uradno prečiščeno besedilo, 102/07, 107/10, 87/11, 40/12 - Z U J F, 63/13 in 46/16 - ZOFVI-L.

Zakon o pacientovih pravicah (z P acP). Uradni list Republike Slovenije, št. $15 / 08$ in $55 / 17$.

Zakon o pravdnem postopku (z P P). Uradni list Republike Slovenije, št. 73/o7 - uradno prečiščeno besedilo, 45/o8 - Z Arbit, 45/o8, 111/o8 - odl. US, 57/og - odl. U , 12/10 - odl. U S, 50/10 - odl. U s, 107/10 - odl. U , 75/12 - odl. U S, 4o/13 - odl. U S, 92/13 - odl. U S, 10/14 - odl. Us in 48/15 odl. U S.

Zakon o splošnem upravnem postopku (z U P). Uradni list Republike Slovenije, št. 24/o6 - uradno prečiščeno besedilo, 105/o6 - Z U S-1, 126/o7, 65/o8, $8 / 10$ in $82 / 13$.

Zakon o varstvu osebnih podatkov (ZVO P-1). Uradni list Republike Slovenije, št. 94/O7 - UP B.

Zakono o zbirkah podatkov s področja zdravstvenega varstva (z Z P P Z). Uradni list Republike Slovenije, št. 65/oo, 47/15 in 31/18.

\section{Protection of Personal Data in the Work of a Psychologist}

It is in nature of psychologist's work that he has to deal with the data of individuals, namely data on their properties, states, relationships and acts. Since these data are usually related to an identified or identifiable natural person, we are talking about personal data. These are subject to the protection of personal data as a special legal regime, regulated in various laws. As for the field of psychology there are no special rules in Slovenia, general rules on protection of personal data apply. One of the exceptions is clinical psychology, which is partially subject of healthcare legislation. Regulation on protection of personal data have a certain impact on the work of psychologist, which is primarily commited to professional secrecy. Although the system of protection of personal data is relatively strict, it is not absolute in the sense that personal data can not be disclosed to anyone. Along with the general rules on non-disclosure and data security, there are some special legal basis available for diclosure of personal data to third parties. On the other hand, psychologists doesn't have many legal basis for obtaining personal information from third parties (external sources), except from the individual. This paper covers some specially selected issues on acquisition, retention and disclosure of personal data of individuals, with an emphasis on individual's rights. 